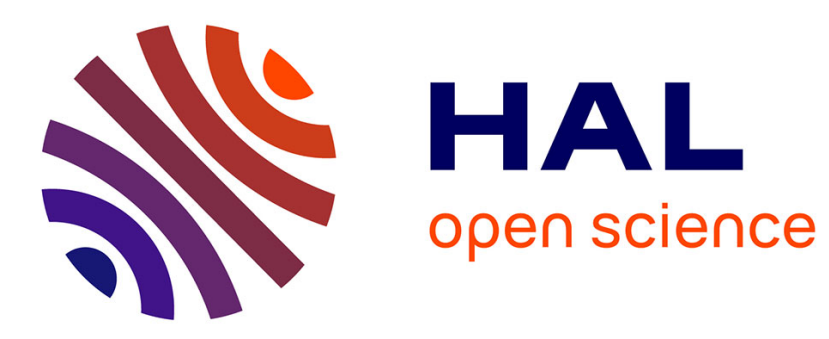

\title{
Biomechanical constraints associated with walking in obese individuals
}

\author{
Nicolas Peyrot
}

\section{To cite this version:}

Nicolas Peyrot. Biomechanical constraints associated with walking in obese individuals. Physical Therapy Reviews, 2012, 17 (5), pp.352-353. 10.1179/1743288X12Y.0000000029 . hal-01232317

\section{HAL Id: hal-01232317 \\ https://hal.univ-reunion.fr/hal-01232317}

Submitted on 28 Oct 2016

HAL is a multi-disciplinary open access archive for the deposit and dissemination of scientific research documents, whether they are published or not. The documents may come from teaching and research institutions in France or abroad, or from public or private research centers.
L'archive ouverte pluridisciplinaire HAL, est destinée au dépôt et à la diffusion de documents scientifiques de niveau recherche, publiés ou non, émanant des établissements d'enseignement et de recherche français ou étrangers, des laboratoires publics ou privés. 


\section{Biomechanical constraints associated with walking in obese individuals}

\section{Nicolas Peyrot}

Laboratoire CURAPS-DIMPS, Faculté des Sciences de l'Homme et de l'Environnement, Université de la Réunion, Le Tampon, La Réunion, France

Invited Commentary on: 'Gait and increased body weight (potential implications for musculoskeletal disease)', Sheehan and Gormley.

Obesity is partly attributable to a low level of physical activity leading to insufficient total daily energy expenditure. Accordingly, increasing levels of physical activity is one of the key challenges in the prevention and treatment of obesity. ${ }^{1}$ To date, studies report only modest adherence to physical activity in obese individuals. ${ }^{2,3}$ These persistently low levels of daily physical activity may be attributed to physiological and biomechanical factors that limit gait performance. ${ }^{4-6}$ For instance, walking is one of the most convenient daily physical activities recommended for increasing energy expenditure. However, obese individuals encounter some limitations during walking such as modifications in the gait pattern, higher net metabolic rate (gross minus standing, W/kg), and pain due to alteration of the musculoskeletal system. ${ }^{4-11}$ As a consequence of the interaction of these characteristics, walking may be a critical source of biomechanical loads that link obesity and musculoskeletal pathology, such as lower-extremity osteoarthritis, rheumatoid arthritis, low back pain, foot

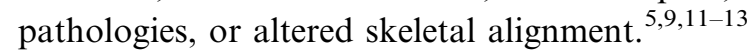

In a recent of the journal of Physical Therapy Reviews, the article by Sheehan and Gormley ${ }^{9}$ stresses the importance of understanding how obesity affects the biomechanical load involved in walking. This could provide appropriate individualized prescription in order to prevent the onset and progression of musculoskeletal diseases. To this end, the authors present the differences in biomechanical gait parameters between normal-weight and obese individuals. In obese children and adults, an increased body weight leads to major modification in the gait pattern. ${ }^{6,7,9-11,13,14}$ Obese individuals adopt a slower preferred walking speed, and spend more time in stance and double-limb

Correspondence to: Nicolas Peyrot, Faculté des Sciences de l'Homme et de l'Environnement, Laboratoire CURAPS-DIMPS, Université de la Réunion, 117 rue du Général Ailleret, F-97430 Le Tampon, La Réunion, France. Email: nicolas.peyrot@univ-reunion.fr support, and less time in swing at all walking speeds. Moreover, obese individuals walk with greater step width. These specific temporal-spatial parameters and the reduced preferred walking speed may be a locomotor strategy to improve gait stability and to prevent falls.

Lower-extremity joint biomechanics is also affected by increased body weight during walking. The association between increased body weight and kinematic adaptations at the hip, knee, and ankle in all three planes of motion (i.e. frontal, sagittal, and transverse) leads to higher joint moments and thus to an increased load across the lower-extremity joints. For instance, Browning and $\mathrm{Kram}^{13}$ have shown that in the frontal plane, a high external knee adduction moment increases the compressive load on the medial compartment of the knee in obese adults. This kneejoint load across the tibiofemoral compartment has been shown to be positively correlated with osteoarthritis disease severity and progression. ${ }^{15}$ Moreover, the peak external knee moment has been shown to increase with walking speed. ${ }^{13}$ Browning and $\mathrm{Kram}^{13}$ therefore proposed that an obese adult would need to walk at about $1.1 \mathrm{~m} / \mathrm{second}$ (close to their preferred walking speed) to have a biomechanically equivalent joint load as normal-weight adults walking at $1.4 \mathrm{~m} / \mathrm{second}$.

Further, Ehlen et al. ${ }^{16}$ pointed out that moderate obese individuals have to walk faster than their preferred walking speed to increase exercise intensity and to follow physical activity guidelines. However, lower-extremity joint loads and the associated risk of musculoskeletal injuries or disease increase with walking speed. To limit this negative effect of increased level walking speed on joint loads, the authors proposed to test whether uphill walking at a slower speed is an alternative form of moderate intensity exercise that may reduce joint loading. They concluded that walking using a treadmill incline (6$\left.9^{\circ}\right)$ at a relatively slow speed $(<0.75 \mathrm{~m} /$ second $)$ is an effective strategy to reduce load across the lowerextremity joints while providing adequate cardiovascular stimulus for weight management. ${ }^{16}$ Moreover, walking at slower speeds and moderate inclines may improve the adherence and the activity time due to a reduced perceived exertion of effort. These studies therefore contribute to the support of appropriate individualized prescription in obese individuals to reduce biomechanical load involved in walking and prevent the onset and progression of musculoskeletal diseases. 
Interestingly, Sheehan and Gormley ${ }^{9}$ report that the reduced muscular strength of the lower limbs in obese individuals could lead to gait adaptations, such as a more erect posture during walking. Hills et al. ${ }^{5}$ also suggested that the reduced muscular strength can impair motor function and limit obese individuals' ability to perform activities of daily living. Further, results of recent studies suggest that the lower relative muscle strength in obese individuals could be partly responsible for the higher net metabolic rate. ${ }^{1,18}$ Future research should assess the effects of biomechanical properties of the lower-extremity muscles on gait performance in obese individuals. This work could have important practical applications for clinicians in the design of appropriate interventions, because strength training could be recommended in obese individuals to improve walking economy, motor function, and gait pattern.

In conclusion, the combination of excess body weight and altered gait biomechanics in obese individuals increases the load applied to the weight-bearing joints during walking. These greater lower-extremity joint loads could be related to the onset of musculoskeletal disorders. For exercise prescription in obese individuals, strategies like walking at a relatively slow speed up a moderate incline should be considered to prevent the onset and progression of musculoskeletal disorders. Further biomechanical research is warranted to assess the source of biomechanical loads and musculoskeletal pain involved in walking and to provide appropriate individualized exercise prescriptions in obese individuals.

\section{References}

1 Hill JO, Wyatt HR. Role of physical activity in preventing and treating obesity. J Appl Physiol. 2005;99(2):765-70.

2 King AC, Kiernan M, Oman RF, Kraemer HC, Hull M, Ahn D. Can we identify who will adhere to long-term physical activity? Signal detection methodology as a potential aid to clinical decision making. Health Psychol. 1997;16(4):380-9.
3 Ekkekakis P, Lind E. Exercise does not feel the same when you are overweight: the impact of self-selected and imposed intensity on affect and exertion. Int $\mathbf{J}$ Obes (Lond). 2006;30(4):652-60.

4 Wearing SC, Hennig EM, Byrne NM, Steele JR, Hills AP. The biomechanics of restricted movement in adult obesity. Obes Rev. 2006;7(1):13-24.

5 Hills AP, Hennig EM, Byrne NM, Steele JR. The biomechanics of adiposity - structural and functional limitations of obesity and implications for movement. Obes Rev. 2002;3(1):35-43.

6 Nantel J, Mathieu ME, Prince F. Physical activity and obesity: biomechanical and physiological key concepts. J Obes. 2011;2011:650230.

7 Malatesta D, Vismara L, Menegoni F, Galli M, Romei M, Capodaglio P. Mechanical external work and recovery at preferred walking speed in obese subjects. Med Sci Sports Exerc. 2009;41(2):426-34

8 Browning RC, Kram R. Pound for pound: working out how obesity influences the energetics of walking. J Appl Physiol. 2009;106(6):1755-6.

9 Sheehan K, Gormley J. Gait and increased body weight (potential implications for musculoskeletal disease). Phys Ther Rev. 2012;17(2):91-98.

10 Peyrot N, Thivel D, Isacco L, Morin JB, Duche P, Belli A. Do mechanical gait parameters explain the higher metabolic cost of walking in obese adolescents? J Appl Physiol. 2009;106(6): 1763-70.

11 Runhaar J, Koes BW, Clockaerts S, Bierma-Zeinstra SM. A systematic review on changed biomechanics of lower extremities in obese individuals: a possible role in development of osteoarthritis. Obes Rev. 2011;12(12):1071-82.

12 Krul M, van der Wouden JC, Schellevis FG, van SuijlekomSmit LW, Koes BW. Musculoskeletal problems in overweight and obese children. Ann Fam Med. 2009;7(4):352-6.

13 Browning RC, Kram R. Effects of obesity on the biomechanics of walking at different speeds. Med Sci Sports Exerc. 2007;39(9):1632-41.

14 Shultz SP, Browning RC, Schutz Y, Maffeis C, Hills AP. Childhood obesity and walking: guidelines and challenges. Int $\mathbf{J}$ Pediatr Obes. 2011;6(5-6):332-41.

15 Miyazaki T, Wada M, Kawahara H, Sato M, Baba H, Shimada $\mathrm{S}$. Dynamic load at baseline can predict radiographic disease progression in medial compartment knee osteoarthritis. Ann Rheum Dis. 2002;61(7):617-22.

16 Ehlen KA, Reiser RF, 2nd, Browning RC. Energetics and biomechanics of inclined treadmill walking in obese adults. Med Sci Sports Exerc. 2011;43(7):1251-9.

17 Hunter GR, McCarthy JP, Bryan DR, Zuckerman PA, Bamman MM, Byrne NM. Increased strength and decreased flexibility are related to reduced oxygen cost of walking. Eur $\mathbf{J}$ Appl Physiol. 2008;104(5):895-901.

18 Peyrot N, Thivel D, Isacco L, Morin JB, Belli A, Duche P. Why does walking economy improve after weight loss in obese adolescents? Med Sci Sports Exerc. 2012;44(4):659-65. 